\title{
Is Penicillin-Nonsusceptible Streptococcus pneumoniae a Significant Challenge to Healthcare System? A Systematic Review and Meta-Analysis
}

\author{
Farzad Khademi ${ }^{1}$ and Amirhossein Sahebkar $\mathbb{D D}^{2,3,4}$ \\ ${ }^{1}$ Department of Microbiology, School of Medicine, Ardabil University of Medical Sciences, Ardabil, Iran \\ ${ }^{2}$ Applied Biomedical Research Center, Mashhad University of Medical Sciences, Mashhad, Iran \\ ${ }^{3}$ Biotechnology Research Center, Pharmaceutical Technology Institute, Mashhad University of Medical Sciences, Mashhad, Iran \\ ${ }^{4}$ School of Pharmacy, Mashhad University of Medical Sciences, Mashhad, Iran
}

Correspondence should be addressed to Amirhossein Sahebkar; amir_saheb2000@yahoo.com

Received 14 January 2021; Accepted 20 May 2021; Published 27 May 2021

Academic Editor: Abdel Halim Salem

Copyright (c) 2021 Farzad Khademi and Amirhossein Sahebkar. This is an open access article distributed under the Creative Commons Attribution License, which permits unrestricted use, distribution, and reproduction in any medium, provided the original work is properly cited.

\begin{abstract}
Background. In recent years, antibiotic-resistant pathogens including penicillin-nonsusceptible Streptococcus pneumoniae (PNSP) have posed serious threats against human health. The aim of this meta-analysis was to investigate the prevalence of Streptococcus pneumoniae drug resistance particularly the incidence of PNSP strains in Iran. Methods. A systematic search was done in national and international electronic databases using Persian and English keywords. Up until May 20, 2020, a total of 58 publications were detected as eligible articles based on the inclusion and exclusion criteria, and then the selected studies were enrolled for data extraction and meta-analysis according to the PRISMA guidelines. Results. A high rate of PNSP (46.9\%) and multidrug-resistant (MDR) S. pneumoniae (45.3\%) in our isolates were evident. Furthermore, total frequency resistance to other drugs in S. pneumoniae was as follows: erythromycin $41.1 \%$, azithromycin $53.2 \%$, tetracycline $39.9 \%$, levofloxacin $1.7 \%$, rifampin $1.2 \%$, clindamycin $31.7 \%$, vancomycin $1.7 \%$, trimethoprim/sulfamethoxazole $63.9 \%$, chloramphenicol $20 \%$, ceftriaxone $10.9 \%$, amoxicillin 30.5\%, ciprofloxacin 8.3\%, imipenem 6.1\%, linezolid 0\%, and cefotaxime $8.3 \%$. Conclusion. Although the overall prevalence of cephalosporin- and carbapenem-resistant Streptococcus pneumoniae was low, penicillin-resistant strains, especially PNSP, could become a significant challenge to the healthcare system in Iran. Hence, the prescription of penicillin as the firstchoice antibiotic in the treatment of $S$. pneumoniae infections should be avoided.
\end{abstract}

\section{Introduction}

Streptococcus pneumoniae (S. pneumoniae) (pneumococcus) is a Gram-positive diplococcus that is an exclusively normal inhabitant in the oropharynx and nasopharynx of healthy individuals $[1,2]$. Colonization rates are higher in the extreme of age (children under 5 and adults older than 65 years old) and immunocompromised patients especially in developing countries [3]. The bacterium enters the body through droplets and aerosols by person-to-person transmission. It then disseminates into other sites including circulation, brain, lungs, paranasal sinuses, and middle ears and causes severe diseases such as pneumonia, sinusitis, otitis media, bacteremia, and meningitis [1-3]. Pneumonia of any cause is an important disease affecting children under the age of five. In 2017, the World Health Organization (WHO) announced 808,694 pneumonia-related child deaths which accounts for $15 \%$ of total mortality in children younger than five years old [4]. The two most common bacterial causes of pneumonia in children are S. pneumoniae and Haemophilus influenzae type b, respectively [3]. Recently, a plan released by the WHO/UNICEF named the Integrated Global Action Plan for the Prevention and Control of Pneumonia and Diarrhea (GAPPD) with the aim of reducing the death rate to less than 3 children per 1000 live births by 2025 [4]. The main strategies to protect, 
prevent, and treat children with pneumococcal pneumonia include exclusive breastfeeding, adequate complementary feeding, hand washing, reducing household air pollution, prevention of HIV, oxygen therapy, vaccinations, and also the administration of appropriate antibiotics [4]. Potent anticapsular pneumococcal vaccines (PPSV23, PCV13, and PCV7) were developed based on the prevalent serotypes of S. pneumoniae; however, they are less effective in developing countries due to different distribution patterns of serotypes by geographic locations [1], and hence, they are not part of the childhood immunization plan in Iran. Over the last several decades, penicillin was the drug of choice for the treatment of pneumococcal diseases $[1,2]$. However, up to $40 \%$ of these bacteria are found to be penicillin-resistant [5]. A list of antibiotic-resistant pathogens was released by WHO in February 2017 that urgently requires effective antibiotics [6]. Penicillin-nonsusceptible S. pneumoniae (PNSP) strains are priority 3 (medium) on the list and known as increasingly drug-resistant pathogens which require further research and development of new antibiotics [6]. Given the distinct geographical distributions, which can affect bacterial phenotypic and genetic characteristics such as drug susceptibility, and self-medication of antibiotics in Iran, the current systematic review and meta-analysis was performed to follow four objectives: (1) to estimate the overall prevalence of $S$. pneumoniae strains resistant to different antibiotics among all age groups in Iran, (2) to determine S. pneumoniae drug resistance in Iranian children, (3) to assess the prevalence of PNSP strains, and (4) to investigate antimicrobial resistance profiles in different provinces of Iran.

\section{Methods}

2.1. Search Strategies. The current systematic review and meta-analysis is designed based on the PRISMA (Preferred Reporting Items for Systematic Reviews and Meta-Analysis) guidelines [7]. A comprehensive search was performed on studies published from October 1993 to May 2020. English keywords in the ISI Web of Knowledge, PubMed, Scopus, and Google Scholar databases and Persian keywords in national search engines including Scientific Information Database (http://www.sid.ir) and Magiran (http://www. Magiran.com) were used to find original articles addressing S. pneumoniae antibiotic resistance in Iran. For this purpose, the search terms (i.e., S. pneumoniae, antibiotic resistance, and Iran) were extracted from Medical Subject Headings (MeSH) and combined with connectors (AND/ OR).

2.2. Inclusion and Exclusion Criteria. The articles were selected based on the title, abstract, and full text. First, the titles of cross-sectional studies on the prevalence of drug resistance were evaluated according to the author, bacterium, and country names, and then, abstracts and full texts were further assessed. Inclusion criteria were original articles assessing the prevalence of pneumococcus drug resistance, full-text availability, publication in English or Persian languages, and studies with sufficient data and limited to Iran. Exclusion criteria were studies reporting drug resistance patterns only at the level of Streptococcus genus or other than S. pneumoniae, evaluating the prevalence of S. pneumoniae resistance with low sample size, repetitive publications, nonoriginal articles, and articles available only in abstract form or abstracts from conferences.

2.3. Quality Assessment and Data Extraction. Included articles were further assessed in terms of quality using the Joanna Briggs Institute (JBI) critical appraisal checklist, and then, necessary data were extracted and tabulated in Table 1 [66]. The main data included the first author's surname, study location, publication date, study enrollment date, age group, sample size, antibiotic susceptibility testing methods, the prevalence of $S$. pneumoniae resistance to different drugs, and the prevalence of multidrug-resistant (MDR) pneumococci.

2.4. Meta-Analysis. Meta-analysis of the extracted data on the S. pneumoniae antibiotic resistance was performed using the Comprehensive Meta-Analysis (CMA) software (Biostat, Englewood, NJ), and the frequency of drug resistance was expressed as the percentage and 95\% confidence intervals (95\% CIs). Further analysis on the location of the study and age groups was also conducted. To evaluate the heterogeneity across the included studies, $I^{2}$ statistics and the chisquare test $\left(\chi^{2}\right)$ with the Cochrane $Q$ statistic ( $Q$ test) ( $p$ value $<0.05$ was considered statistically significant) were used. A random-effects model (DerSimonian-Laird method) was used to pool the data when heterogeneity was considered high $\left(I^{2} \geq 25 \%\right)$. Distribution bias among published studies was calculated quantitatively using Begg's and Egger's tests ( $p$ value $<0.05$ indicates a significant bias) and visualized via the funnel plot graphs for each antibiotic.

\section{Results}

3.1. Results of Search and Characteristics of the Included Articles. Data were available from 15 provinces as follows: Ardabil $(n=1)$, Chaharmahal and Bakhtiari $(n=2)$, East Azerbaijan $(n=1)$, Fars $(n=6)$, Golestan $(n=1)$, Hamadan $(n=5)$, Isfahan $(n=2)$, Kermanshah $(n=1)$, Khuzestan $(n=1)$, Qazvin $(n=1)$, Tehran $(n=31)$, Sistan and Balouchastan $(n=3)$, West Azerbaijan $(n=1)$, Yazd $(n=1)$, and Zanjan $(n=1)$. Detailed characteristics of the selected articles are summarized in Table 1. A total of 1249 reports were identified for the analysis of $S$. pneumoniae antibiotic resistance in Iran. Finally, 58 articles (50 in English and 8 in Persian) were included in the study (Figure 1). Disk diffusion, E-test, and broth micro- and macrodilution were the most common methods used for antimicrobial susceptibility testing in the included articles.

3.2. Total S. pneumoniae Drug Resistance in Iran. The pooled prevalence of $S$. pneumoniae resistance to various antibiotics including erythromycin, azithromycin, tetracycline, 


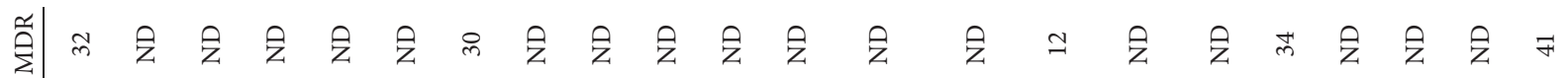

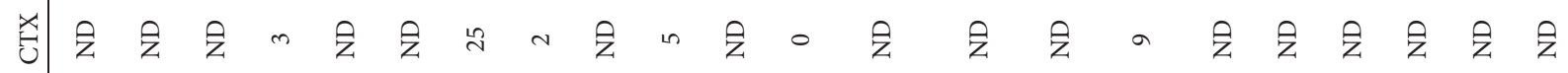

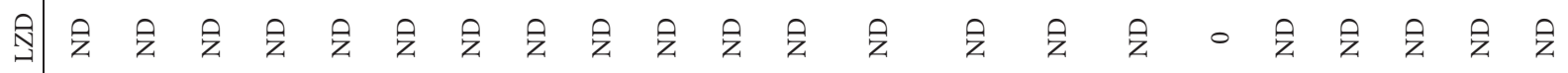

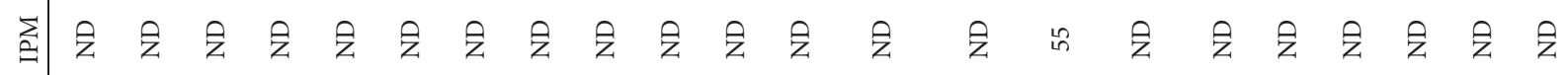

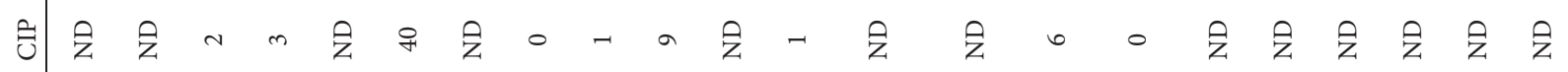

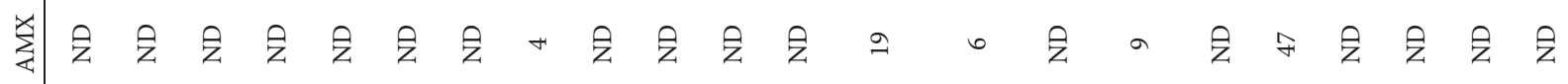

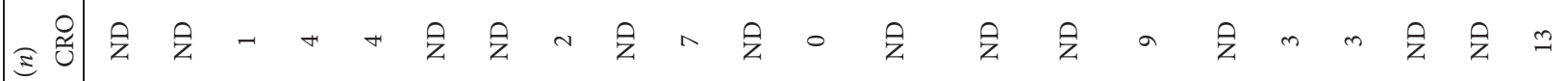

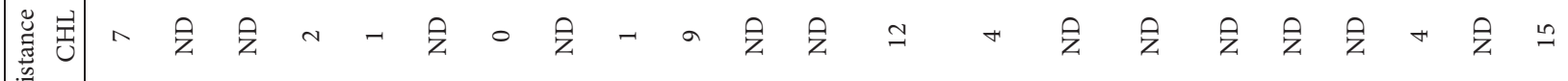

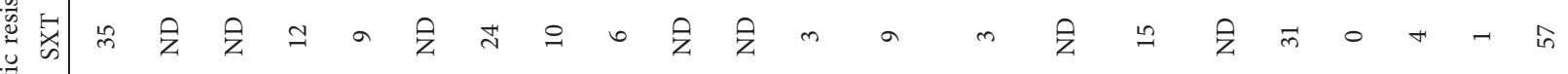

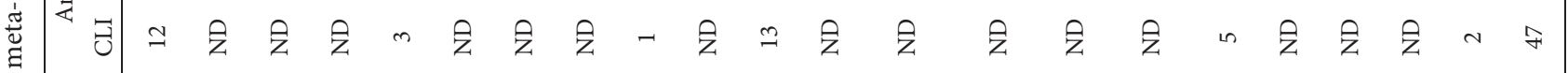

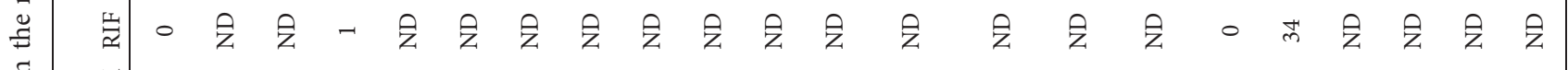

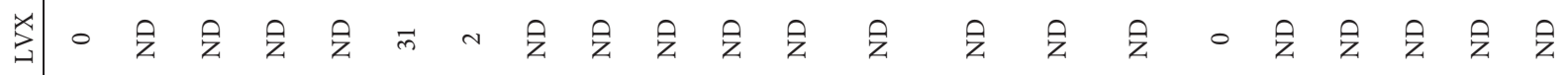

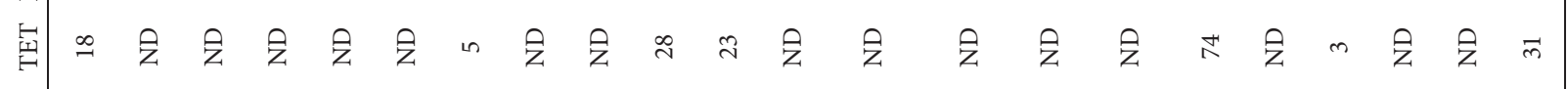

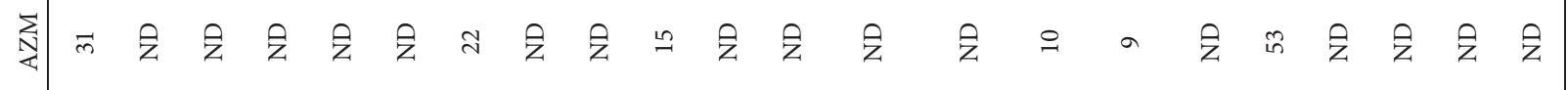
啇

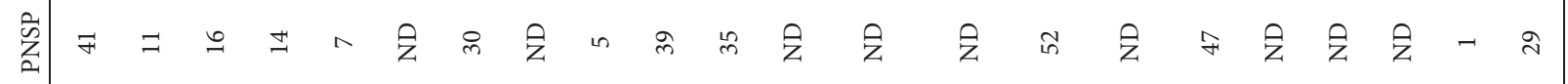

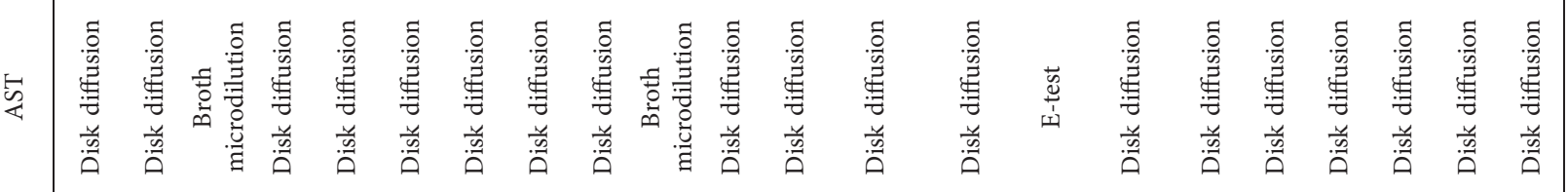

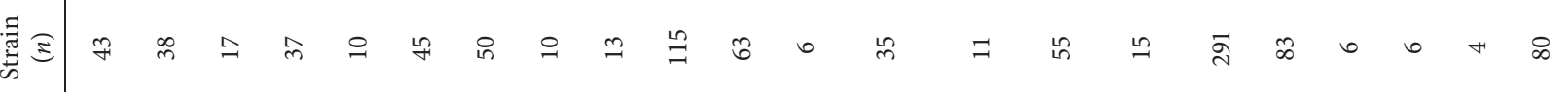

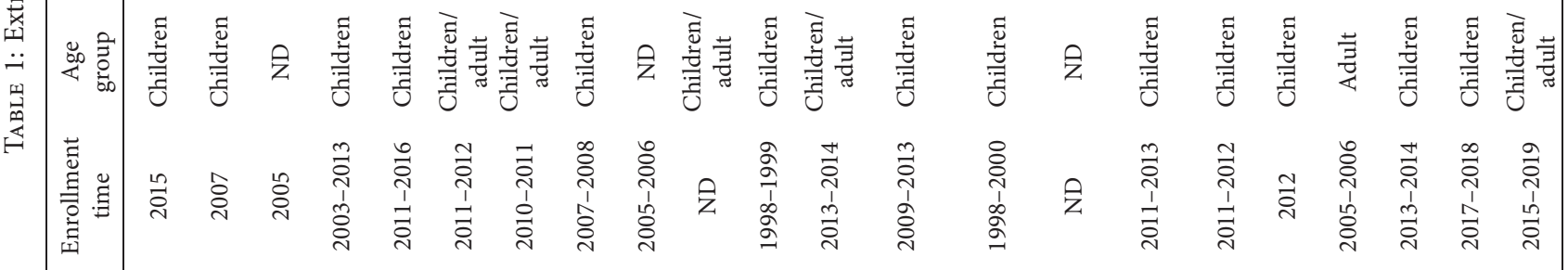

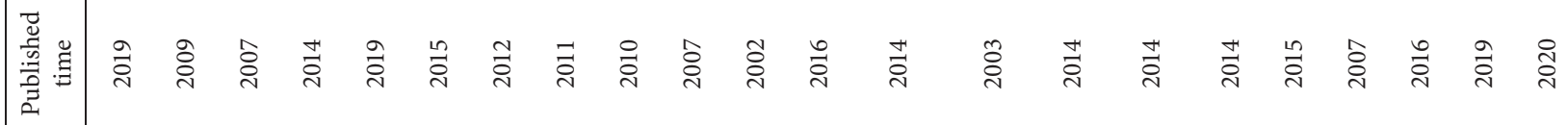

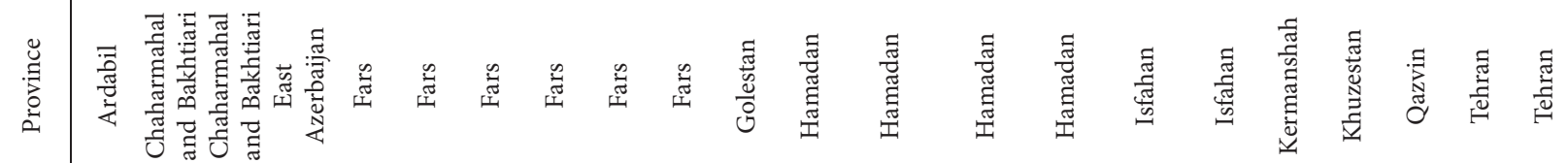

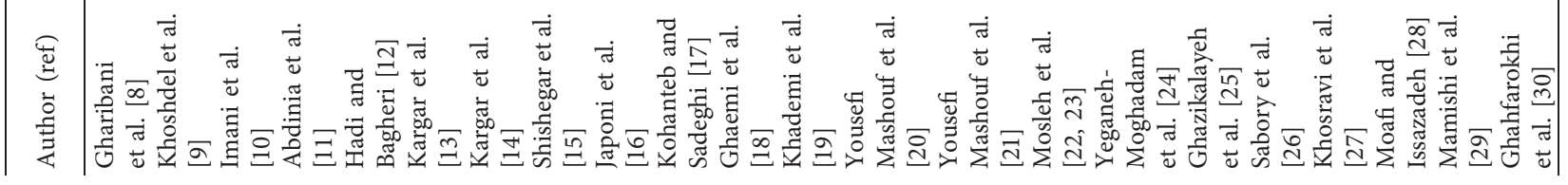




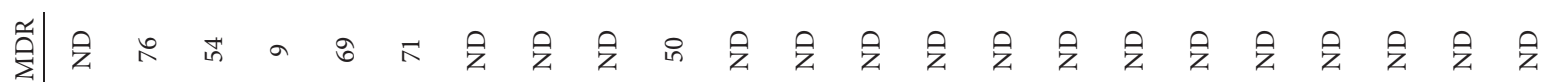

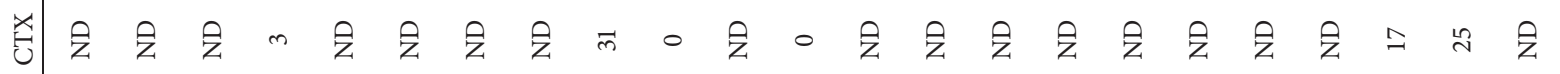

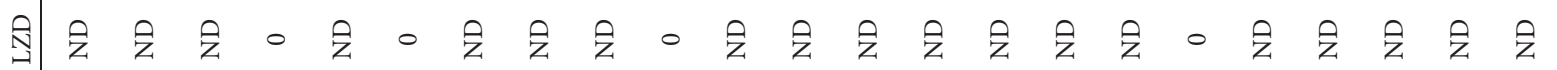

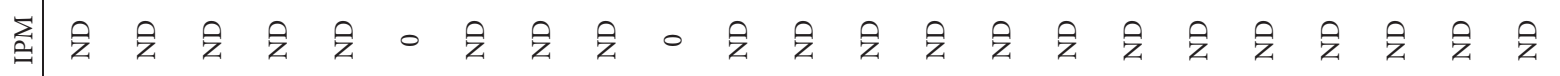

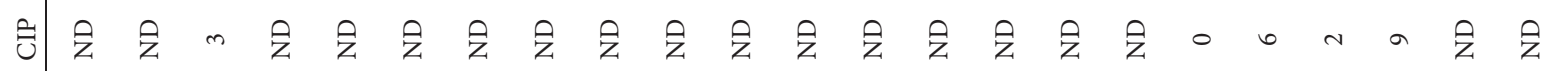

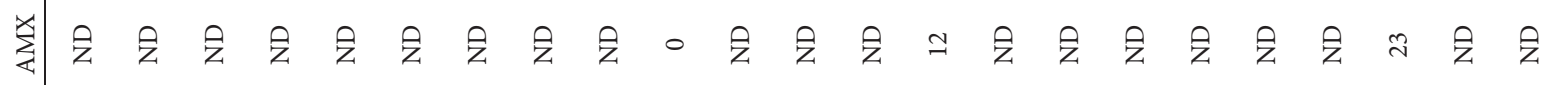

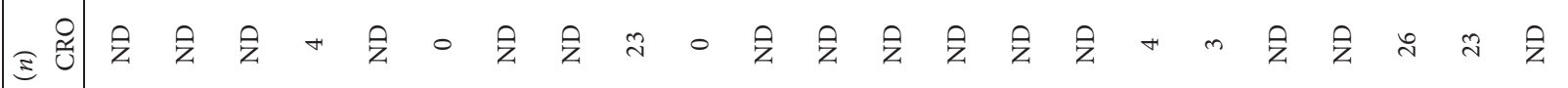

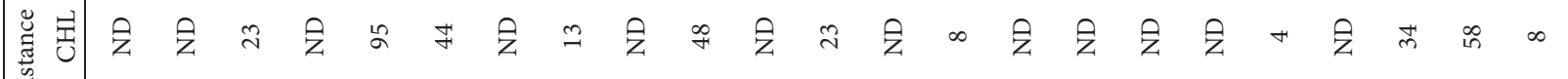

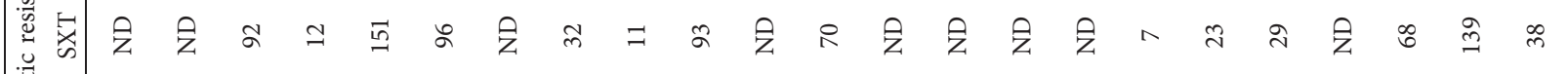

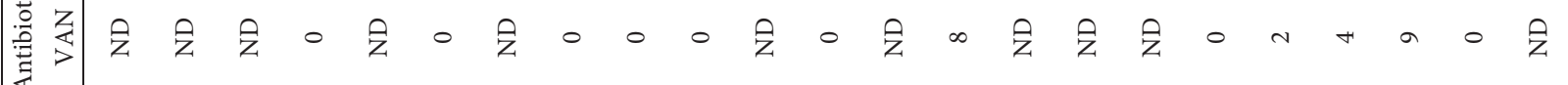

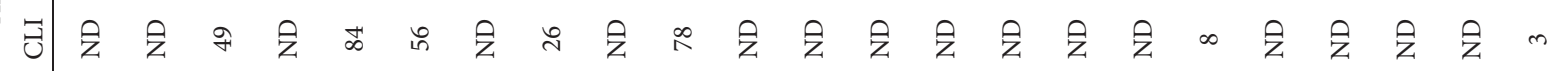

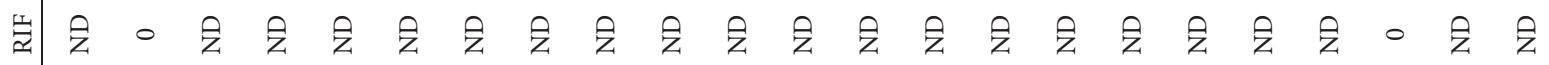

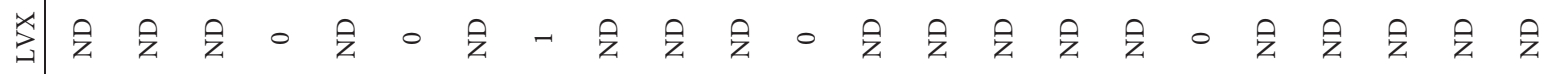

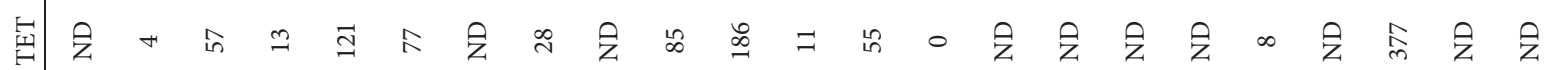

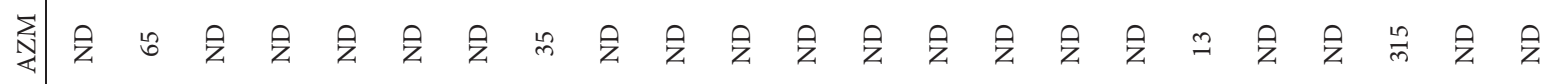

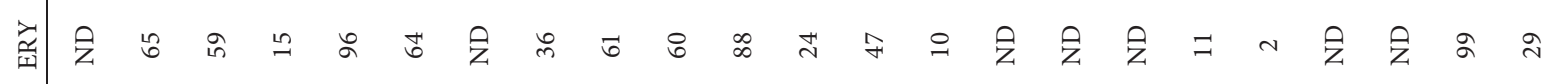

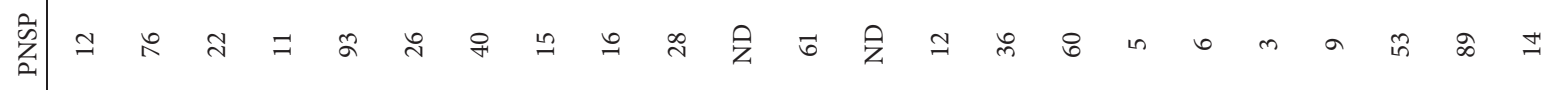

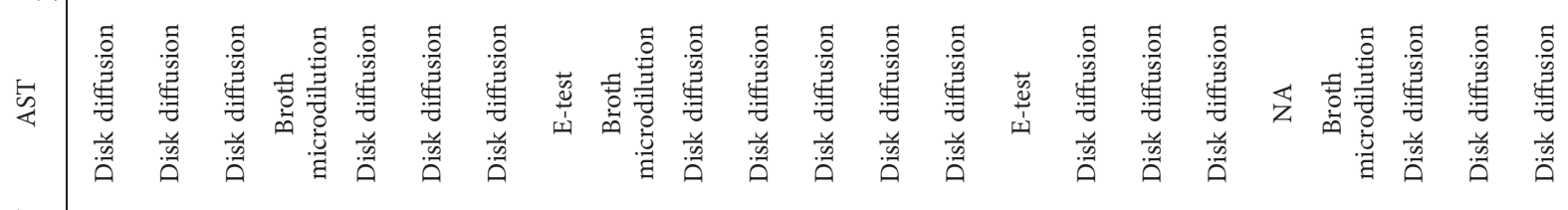

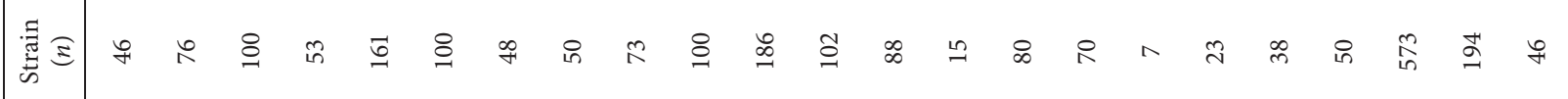

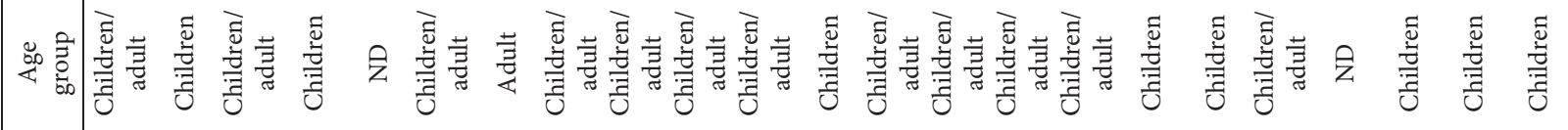

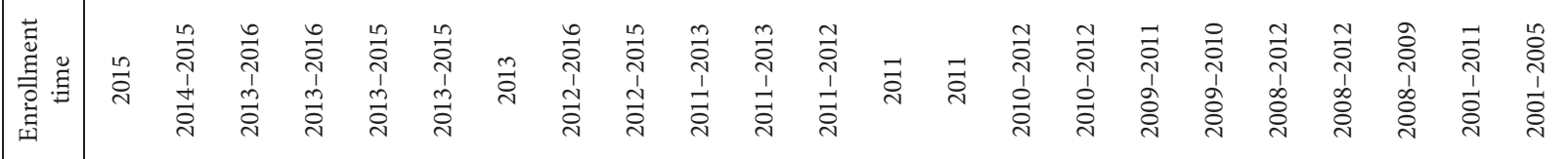

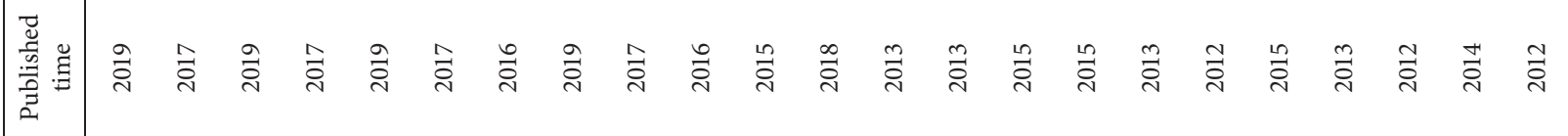

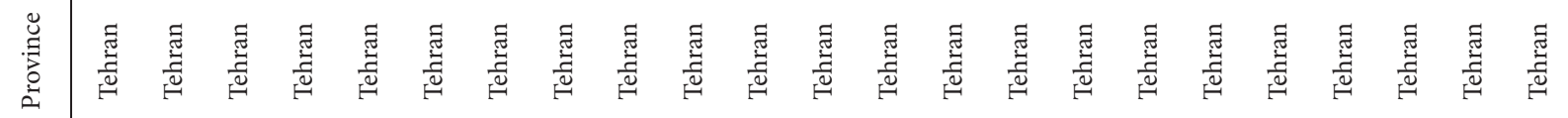

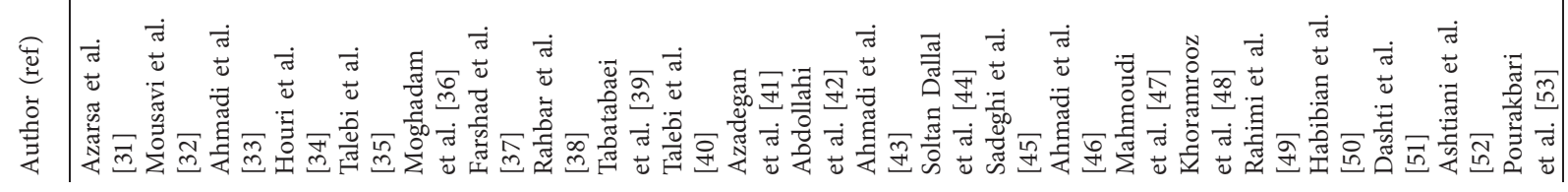




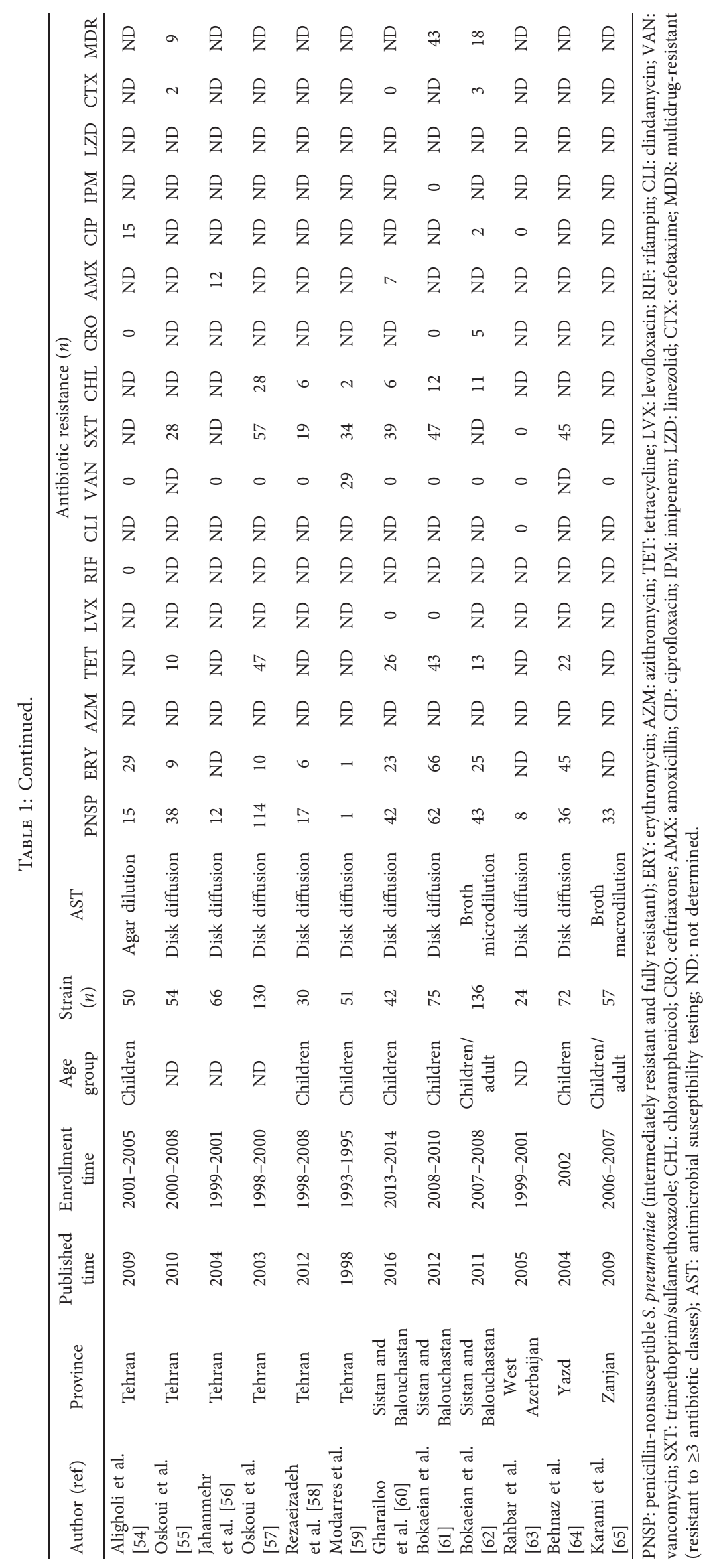




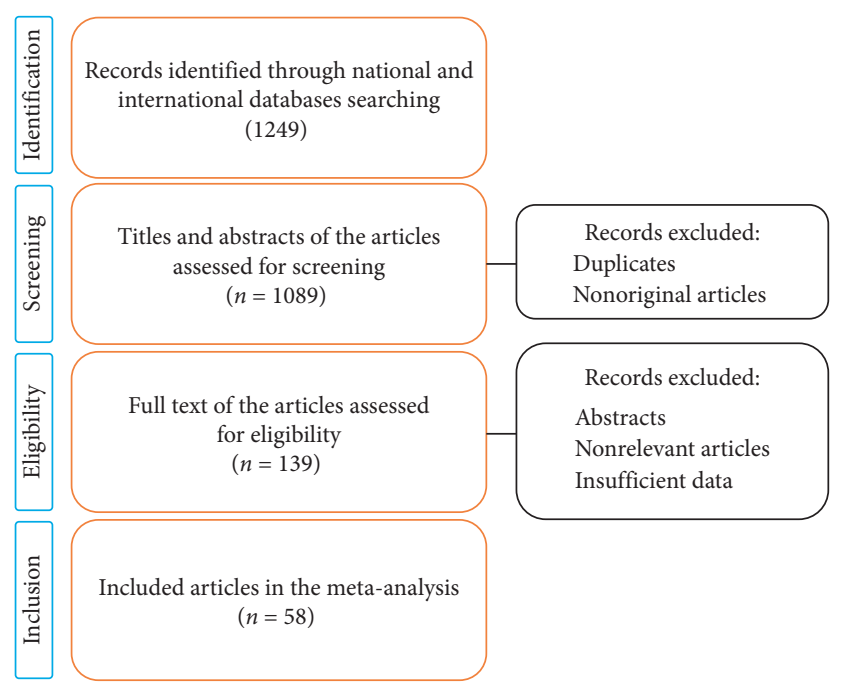

Figure 1: Flow diagram of literature search and study selection.

levofloxacin, rifampin, clindamycin, vancomycin, trimethoprim/sulfamethoxazole, chloramphenicol, ceftriaxone, amoxicillin, ciprofloxacin, imipenem, linezolid, and cefotaxime was $41.1 \%$ (95\% CI: 32.9-49.7; $I^{2}=93 \%$; $Q=545.1$; $p=0.00), 53.2 \%$ (95\% CI: 38.9-67.1; $I^{2}=92.4 \% ; Q=118.4$; $p=0.00), 39.9 \%$ (95\% CI: 30.2-50.4; $I^{2}=95 \% ; Q=506.8$; $p=0.00), 1.7 \% \quad\left(95 \%\right.$ CI: $0.2-11.1 ; I^{2}=90.9 \% ; Q=110 ;$ $p=0.00), 1.2 \% \quad\left(95 \%\right.$ CI: $0.1-13.2 ; I^{2}=91.1 \% ; Q=67.6$; $p=0.00), 31.7 \%$ (95\% CI: 20.7-45.2; $I^{2}=91.9 \% ; Q=172.8$; $p=0.00), 1.7 \% \quad\left(95 \%\right.$ CI: $0.7-4.1 ; I^{2}=85.8 \% ; Q=218.4$; $p=0.00), 63.9 \%\left(95 \% C I: 52.3-74 ; I^{2}=94.6 \% ; Q=672.5\right.$; $p=0.00), 20 \%$ (95\% CI: 14.2-27.3; $I^{2}=91.4 \% ; Q=303.5$; $p=0.00), 10.9 \%$ (95\% CI: 6.6-17.6; $I^{2}=84.7 \% ; Q=130.8$; $p=0.00), 30.5 \%$ (95\% CI: $12.8-56.8 ; I^{2}=95.2 \% ; Q=187.6$; $p=0.00), 8.3 \%$ (95\% CI: 3.6-17.7; $I^{2}=89.6 \% ; Q=154.3$; $p=0.00), 6.1 \% \quad\left(95 \%\right.$ CI: $0.1-89.4 ; I^{2}=91.8 \% ; Q=36.6$; $p=0.00), 0 \%$, and $8.3 \%$ (95\% CI: $3.7-17.4 ; I^{2}=92.5 \%$; $Q=189 ; p=0.00)$, respectively. The frequency of MDR S. pneumoniae strains in Iran was $45.3 \%$ (95\% CI: 34.3-56.8; $\left.I^{2}=91.3 \% ; Q=150.7 ; p=0.00\right)$. As illustrated in Figure 2, the prevalence of MDR S. pneumoniae in Iran showed an increasing trend from $16.7 \%$ in 2010 to $51.3 \%$ in 2020. A random-effects model was used to estimate pooled effect in terms of the heterogeneity among studies.

3.3. S. pneumoniae Drug Resistance in Different Provinces of Iran. The results of the subgroup analysis of the prevalence of $S$. pneumoniae antibiotic resistance based on the different geographic locations in Iran are shown in Table 2. A random-effects model was used to combine studies within each subgroup and obtain the overall effect. The highest rates of S. pneumoniae antibiotic resistance among different provinces in Iran were as follows: $74.4 \%$ to erythromycin in Ardabil, $72.1 \%$ to azithromycin in Ardabil, 50\% to tetracycline in Khuzestan, 24.2\% to levofloxacin in Fars, $41 \%$ to rifampin in Kermanshah, $50.1 \%$ to clindamycin in Tehran, $2.5 \%$ to vancomycin in Hamadan, $96.9 \%$ to trimethoprim/sulfamethoxazole in Isfahan, $66.7 \%$ to

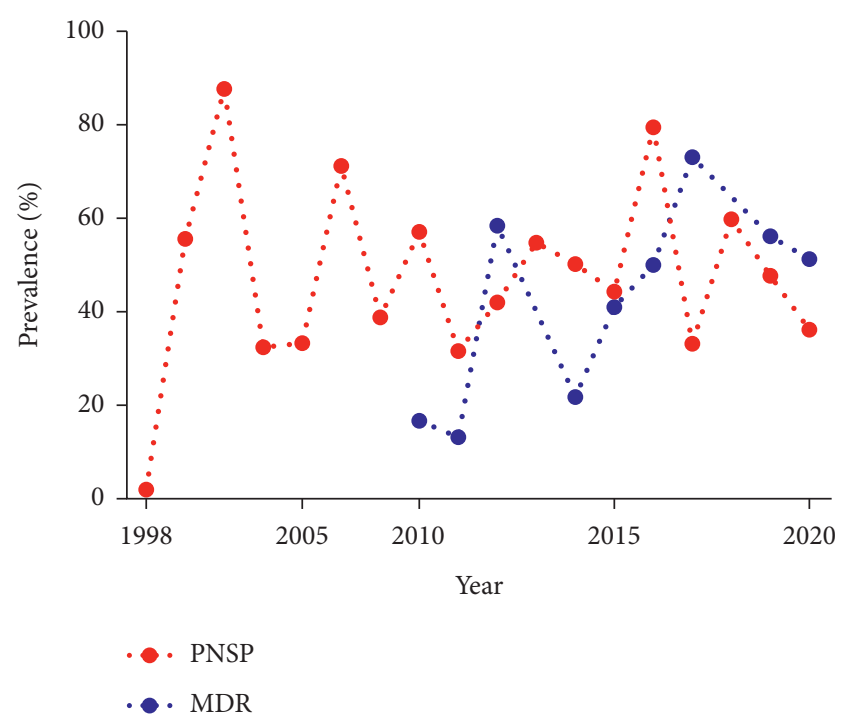

FIgURE 2: Total trend in the prevalence rate of PNSP and MDR strains in all age groups in Iran over time (based on the year of publication).

chloramphenicol in Qazvin, 60\% to ceftriaxone in Isfahan, $60 \%$ to amoxicillin in Isfahan, $20.1 \%$ to ciprofloxacin in Fars, $99.1 \%$ to imipenem in Hamadan, and $60 \%$ to cefotaxime in Isfahan. In addition, the highest rates of PNSP and MDR S. pneumoniae strains were detected in Ardabil (95.3\% and 74.4\%, respectively).

3.4. S. pneumoniae Drug Resistance in Iranian Children. The results of subgroup analysis based on the age group indicated that 27 studies investigated the prevalence of S. pneumoniae antibiotic resistance profiles in Iranian children. Based on the current meta-analysis, S. pneumoniae resistance to different antibiotics was as follows: $38.5 \%(95 \%$ CI: $\left.25.7-53.2 ; I^{2}=93.4 \% ; Q=290.2 ; p=0.00\right)$ to erythromycin, $66.5 \% \quad\left(95 \%\right.$ CI: $54.8-76.5 ; \quad I^{2}=81 \% ; \quad Q=26.4$; $p=0.00)$ to azithromycin, $33 \%$ (95\% CI: 20.2-49; $\left.I^{2}=95.9 \% ; Q=223.1 ; p=0.00\right)$ to tetracycline, $0.8 \%(95 \%$ CI: $\left.0.3-2.1 ; I^{2}=0.0 \% ; Q=1.9 ; p=0.92\right)$ to levofloxacin, $1.2 \%$ (95\% CI: $\left.0.1-13.2 ; I^{2}=91.1 \% ; Q=67.6 ; p=0.00\right)$ to rifampin, $17.3 \%$ (95\% CI: 7.3-35.6; $I^{2}=86.8 \% ; Q=45.5 ; p=0.00$ ) to clindamycin, $1.7 \%$ (95\% CI: $0.4-7.1 ; I^{2}=90.7 \% ; Q=151$; $p=0.00)$ to vancomycin, $63.7 \%$ (95\% CI: $48.3-76.7$; $\left.I^{2}=94.8 \% ; Q=407.2 ; p=0.00\right)$ to trimethoprim/sulfamethoxazole, $17.7 \%$ (95\% CI: $11.4-26.3 ; I^{2}=86.1 \%$; $Q=93.6$; $p=0.00)$ to chloramphenicol, $12.6 \%$ (95\% CI: $6.5-22.9$; $\left.I^{2}=84.9 \% ; Q=73 ; p=0.00\right)$ to ceftriaxone, $35.1 \%$ (95\% CI: $\left.12.3-67.6 ; I^{2}=96.3 \% ; Q=162.4 ; p=0.00\right)$ to amoxicillin, 5.5\% (95\% CI: $\left.1.1-22.7 ; I^{2}=90.7 \% ; Q=53.7 ; p=0.00\right)$ to ciprofloxacin, $0.7 \%$ (95\% CI: $0.0-9.7 ; I^{2}=0.0 \% ; Q=0.0$; $p=1.00)$ to imipenem, $0 \%$ to linezolid, and $8.3 \%$ (95\% CI: $\left.3.2-19.8 ; I^{2}=88.6 \% ; Q=61.4 ; p=0.00\right)$ to cefotaxime. Besides, 57.4\% (95\% CI: 33.1-78.6; $I^{2}=91 \% ; Q=44.8 ; p=0.00$ ) of $S$. pneumoniae isolated from Iranian children were MDR strains. Random- or fixed-effects models were used to estimate pooled effect. 
TABle 2: S. pneumoniae antibiotic resistance profiles in different provinces of Iran.

\begin{tabular}{|c|c|c|c|c|c|c|c|c|c|c|c|c|c|c|c|c|c|}
\hline \multirow{2}{*}{ Province } & \multicolumn{17}{|c|}{ Antibiotic resistance (\%) } \\
\hline & NSP & ERY & $\mathrm{AZM}$ & TET & LVX & RIF & CLI & VAN & SXT & $\mathrm{CHL}$ & $\mathrm{CRO}$ & AMX & CIP & IPM & LZD & CTX & MDR \\
\hline rdabil & 5.3 & 74.4 & 2.1 & 41.9 & .1 & 1.1 & 27.9 & .1 & 1.4 & 6.3 & $\mathrm{ND}$ & ND & ND & ND & ND & ND & 74.4 \\
\hline $\begin{array}{l}\text { Chaharmahal and } \\
\text { akhtiari }\end{array}$ & 69.2 & 58.8 & $\Gamma$ & NI & ND & ND & ND & $\mathrm{N}$ & ND & ND & 9 & ND & 11.8 & ND & ND & ND & ND \\
\hline Zast Azerbaijan & 7.8 & 16.2 & ND & ND & ND & 2.7 & $\mathrm{ND}$ & 1.3 & 32.4 & 5.4 & 10.8 & ND & 8.1 & ND & $\mathrm{ND}$ & 8.1 & ND \\
\hline ars & 48.6 & 27.4 & 25.5 & 17 & 24.2 & ND & 18.5 & 1.9 & 66.2 & 7.3 & 17.1 & 40 & 20.1 & ND & ND & 18.6 & 60 \\
\hline Jolestan & 55.6 & 7.9 & ND & 36.5 & ND & $\mathrm{ND}$ & 20.6 & ND & ND & $\mathrm{ND}$ & ND & ND & ND & ND & $\mathrm{ND}$ & ND & ND \\
\hline I & 4.5 & 25.5 & 18.2 & ND & ND & $\mathrm{ND}$ & ND & 2.5 & 29.1 & 34.8 & 7. & 54.3 & 11.6 & 99.1 & ND & 7.1 & 21.8 \\
\hline$n$ & 16.2 & 11.4 & 60 & 25.4 & 0.2 & 0.2 & 1.7 & 0.2 & 96.9 & ND & 6 & 60 & 3.1 & ND & 0 & 60 & ND \\
\hline Ker & JD & ND & 63.9 & ND & ND & 41 & ND & ND & 37.3 & ND & 3.6 & 56.6 & ND & ND & ND & ND & 41 \\
\hline Khuz & ND & $\mathrm{ND}$ & ND & 50 & ND & $\mathrm{ND}$ & ND & ND & 7.1 & ND & 50 & ND & ND & ND & ND & ND & ND \\
\hline Qazv & ND & ND & ND & ND & ND & $\mathrm{ND}$ & ND & ND & 66.7 & 66.7 & $\mathrm{ND}$ & ND & ND & ND & ND & ND & $\mathrm{ND}$ \\
\hline Tehran & 40.2 & 47.3 & 68.1 & 45.7 & 1.1 & 0.4 & 50.1 & 2.2 & 69.5 & 24.1 & 9.8 & 12.8 & 5.9 & 0.5 & 0 & 5.4 & 47 \\
\hline Sistan a & 79.3 & 55.4 & ND & 38.1 & 0.9 & $\mathrm{ND}$ & ND & 0.7 & 81.3 & 12.1 & 2.6 & 16.7 & 1.5 & 0.7 & ND & 2 & 31.2 \\
\hline West & 33.3 & ND & ND & ND & ND & ND & 2 & 0.2 & 2 & ND & $\mathrm{ND}$ & ND & 2 & ND & ND & ND & ND \\
\hline Yazd & 50 & 62.5 & ND & 30.6 & ND & ND & ND & ND & 62.5 & ND & ND & ND & ND & ND & ND & ND & ND \\
\hline Zanjan & 57.8 & ND & ND & ND & ND & ND & ND & 0.9 & ND & $\mathrm{ND}$ & $\mathrm{ND}$ & ND & ND & ND & $\mathrm{ND}$ & ND & ND \\
\hline
\end{tabular}

3.5. Penicillin-Nonsusceptible S. pneumoniae in Iran. According to the random-effects model $\left(I^{2}=93.6 \%\right.$; $Q=712.6 ; p=0.00)$, the total prevalence of PNSP strains in Iran was $46.9 \%$ (95\% CI: 38.6-55.4). In addition, the rate of PNSP strains isolated from Iranian children was 46.9\% (95\% CI: $\left.33.4-60.8 ; \quad I^{2}=94.4 \% ; Q=363.1 ; p=0.00\right)$ as well (Figure 3(a)). As shown in Figure 3(b), publication bias was detected in the current study due to the evidence of asymmetry in the funnel plot whereas the results of Begg's $(z=0.21, p=0.83)$ and Egger's tests $(t=1.86, p=0.07)$ were not statistically significant. Finally, as presented in Figure 2, we assessed the frequency of PNSP strains from 1998 to 2020. Figure 2 shows an increasing trend of PNSP strains in Iran.

\section{Discussion}

Antibiotic resistance is consistently growing and has become a global public health crisis. According to the European Center for Disease Prevention and Control (ECDC) and the Center for Disease Control and Prevention (CDC), antibiotic-resistant bacteria in Europe and the USA are associated with an annual mortality rate of 25,000 and 23,000 , respectively. Also, nearly 700,000 deaths worldwide are due to antibiotic resistance $[5,67]$. It is estimated that antimicrobial resistance will lead to 10 million deaths a year by 2050 $[5,67]$. Factors such as antibiotic overuse/misuse in humans and also in the food/veterinary industry along with reduced development of new antibiotics play key roles in the incidence of both Gram-positive and Gram-negative resistant bacteria [5]. Penicillin-resistant S. pneumonia was first detected in Australia in 1967. PNSP strains are listed as one of the most serious emerging bacterial threats as of 2017 [3, 6]. The current rate of penicillin-resistant S. pneumoniae in Iran is $46.9 \%$, whereas it is found to be $1-5 \%$ in the UK, Germany, Austria, Norway, and Sweden, $5-10 \%$ in Italy, $10-25 \%$ in Portugal, Ireland, Finland, and Turkey, 25-50\% in Spain, France, Greece, and Israel, 20\% in Brazil, and 66.4\% in China [68-70]. The results of subgroup analysis based on the age group showed a similarly high rate of PNSP among Iranian children $(46.9 \%)$ which could be due to the common use of antibiotics in these patients [39]. Therefore, the prescription of penicillin as the first-choice antibiotic in the treatment of S. pneumoniae infections such as meningitis and pneumonia should be avoided. The prevalence of PNSP isolates in Iran has shown a rising trend from 1998 to 2020 (Figure 2). While there was high pneumococcal resistance to amoxicillin in Iran, resistance to other beta-lactam antibiotics such as cephalosporins and carbapenems was rather low. Thus, the extended-spectrum cephalosporins are suitable alternative drugs in the treatment of penicillin-resistant infections including pneumococcal meningitis in Iran. Modification of penicillin-binding proteins (PBPs) particularly PBP1a, $\mathrm{PBP} 2 \mathrm{x}$, and PBP2b as well as mutations in $c p o A, c i a H$, murM, and murN genes has been described as the main mechanisms of resistance in S. pneumoniae to beta-lactam antibiotics [3]. Pneumococcal resistance to macrolides, fluoroquinolones, and tetracyclines has also been reported [1]. The prevalence of macrolide-resistant S. pneumoniae is geographically variable as it ranges from 25 to $50 \%$ in France, Italy, and Greece, 10 to $25 \%$ in Spain, Portugal, the UK, Germany, Poland, Norway, and Finland, and 1 to $5 \%$ in Latvia and Sweden [68]. In Iran, $41.1 \%$ and $53.2 \%$ of S. pneumoniae isolates were resistant to erythromycin and azithromycin, respectively. Ribosomal modification, efflux system, and point mutations are involved in the emergence of macrolide-resistant S. pneumoniae [3]. An important mechanism of $S$. pneumoniae resistance to clindamycin is the alteration of the ribosomal target through $\operatorname{erm}(B)$ gene which encodes a 23S RNA methylase [71]. Clindamycin has shown a strong activity against community-acquired infections of S. pneumoniae [71]. However, the rates of clindamycin-resistant pneumococcal strains in the current study were high $(31.7 \%)$ and included $25 \%$ in Egypt, $35.1 \%$ in Turkey, and $21.8 \%$ in the United States $[3,71]$. Penicillins and macrolides have been largely applied in the treatment of community-acquired pneumonia and other respiratory tract infections by $S$. pneumoniae [72]. However, a high resistance 


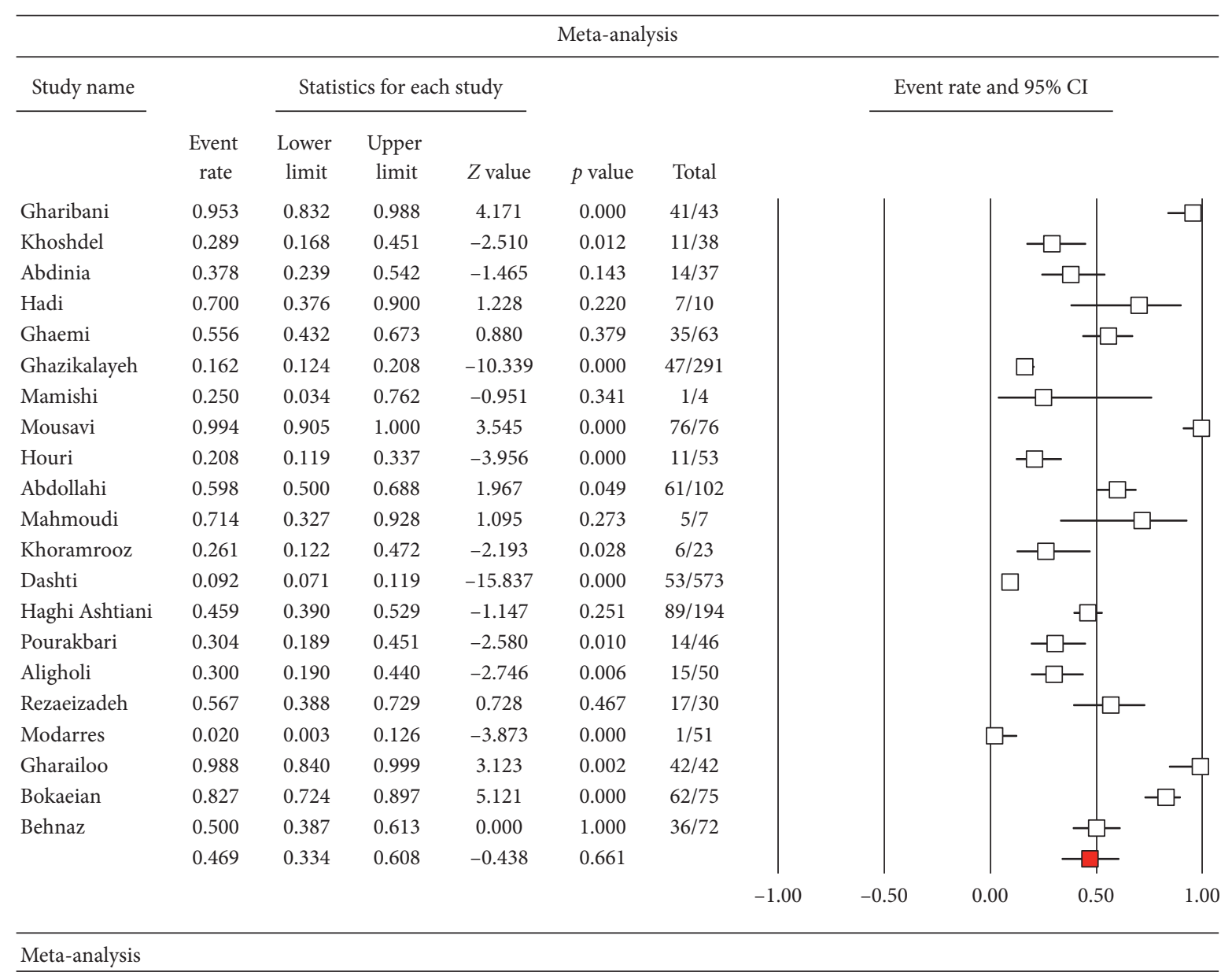

(a)

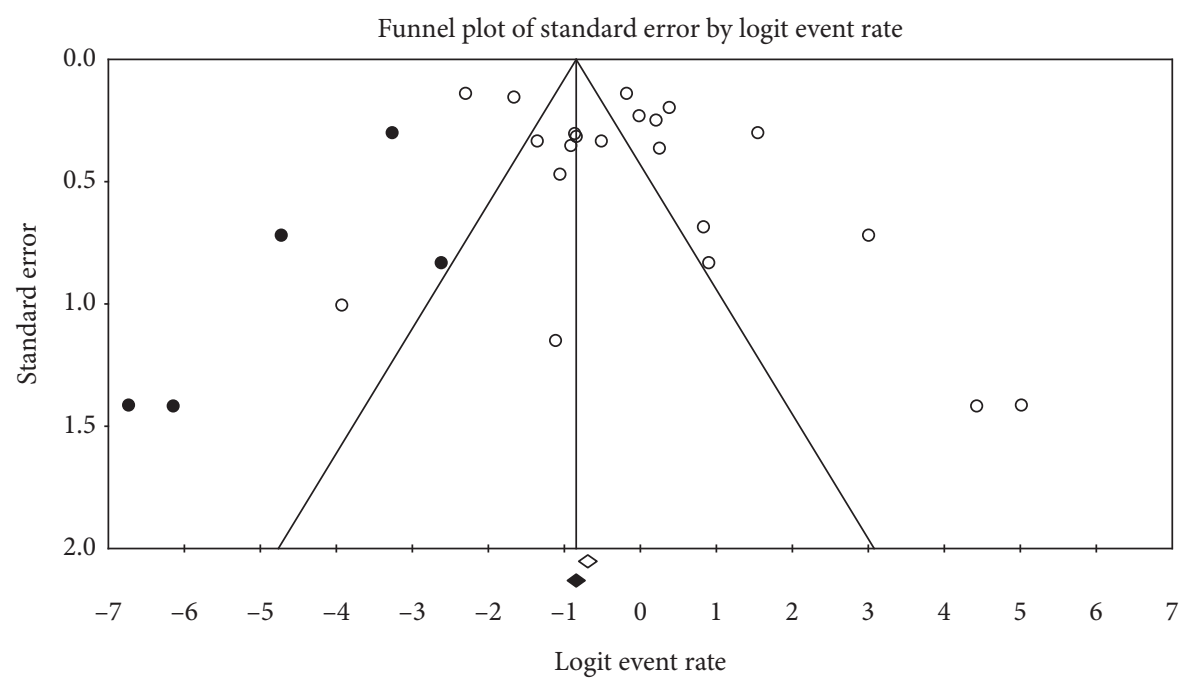

(b)

FIgURE 3: Forest plot (a) and funnel plot (b) showing the prevalence of penicillin-nonsusceptible S. pneumoniae in Iranian children.

rate to these antibiotics has led to the use of quinolones against important bacterial respiratory tract pathogens [72]. Hence, a combination of vancomycin and gentamicin is proposed for treating infections caused by penicillin- and cephalosporin-resistant S. pneumoniae strains [3]. The findings of the present study on the prevalence of fluoroquinolone-resistant strains of $S$. pneumoniae indicated a low resistance rate to levofloxacin $(1.7 \%)$ and ciprofloxacin (8.3\%) in Iran. The prevalence of fluoroquinolone-resistant pneumococcal strains in other countries was as follows: $4 \%$ 
in Egypt, $1.8 \%$ in Turkey, $1-2 \%$ in the USA, and $<10 \%$ in Belgium [3, 71, 72]. A low incidence of vancomycin-resistant S. pneumoniae was found in Iran (1.7\%), and no resistance has been reported in many other countries [3]. Factors associated with resistance to fluoroquinolones in clinical pneumococcal isolates include mutations in the quinoloneresistance-determining regions (QRDRs) of $g y r A, g y r B$, parC, and parE genes as well as the overexpression of $p m r A$ gene (codes for an efflux pump) and pat $A$ and pat $B$ genes (code for an $A B C$ transporter) [3, 71]. Point mutation in a histidine kinase gene $(v n c S)$ is associated with the emergence of vancomycin-tolerant pneumococcal strains [3]. The highest drug resistance rate among pneumococcal isolates in Iran was observed to folate pathway inhibitors (i.e., trimethoprim/sulfamethoxazole (63.9\%)). Cotrimoxazole-resistant S. pneumoniae were isolated in $25-45 \%$ of strains in the USA, 55\% in Egypt, 100\% in Saudi Arabia, and 67.2\% in Turkey [3, 71]. Mutations in dihydrofolate reductase (DHFR) and in dihydropteroate synthase (DHPS) are the mechanisms of resistance to folate inhibitors [3, 71]. Studies from the Middle East and the USA have reported a high rate of $S$. pneumoniae resistance to tetracycline which could be attributed to extensive use of this antimicrobial agent $[3,71]$. A similar result was observed in the current study (39.9\%). Resistance to chloramphenicol (a bacterial protein inhibitor) was high whereas there was no resistance to linezolid. Two other important findings of the study included a high prevalence of MDR pneumococci in Iranian people (45.3\%), especially children (57.4\%) with a rising trend from 2010 to 2020 (Figure 2), and also the isolation of S. pneumoniae resistant to many drugs (such as erythromycin, azithromycin, tetracycline, trimethoprim/sulfamethoxazole, and amoxicillin) in Iranian children. Available data from CDC showed that MDR S. pneumoniae is responsible for more than $30 \%$ of invasive pneumococcal disease throughout the United States [73, 74]. Therefore, timely vaccination in Iranian children and ongoing surveillance on drug resistance trend along with the use of combination therapy or the use of newer antibiotics are needed to improve microorganism susceptibility.

\section{Conclusion}

The current study indicated a high prevalence of PNSP and MDR strains in Iran among all age groups. Similar results were also observed in the frequency of erythromycin-, azithromycin-, tetracycline-, clindamycin-, trimethoprim/ sulfamethoxazole-, chloramphenicol-, and amoxicillin-resistant $S$. pneumoniae strains. These findings could be due to the high consumption of nonprescribed antibiotics in Iran. Hence, strategies to prevent emerging drug-resistant pneumococcal infections and treatment failure in Iran include (1) continuous regional monitoring of nasopharyngeal carriers of antibiotic-resistant S. pneumoniae in children, (2) controlled administration of antibiotics to improve microorganism susceptibility, (3) use of combination therapies or drugs with low resistance rate in accordance with local resistance patterns, and (4) identification of the most common pneumococcal serotypes and their drug resistance rates in Iranian population to produce effective pneumococcal vaccines. The most effective antibiotics for the treatment of pneumococcal infections in Iran based on the current study are levofloxacin, rifampin, vancomycin, ceftriaxone, ciprofloxacin, imipenem, linezolid, and cefotaxime.

\section{Data Availability}

There are no raw data associated with this systematic review and meta-analysis.

\section{Conflicts of Interest}

The authors declare that there are no conflicts of interest.

\section{References}

[1] P. R. Murray, K. S. Rosenthal, and M. A. Pfaller, Medical Microbiologypp. 195-199, Elsevier Health Sciences, London, UK, 8th edition, 2015.

[2] K. C. Carroll, J. S. Butel, and S. A. Morse, Jawetz Melnick \& Adelbergs Medical Microbiologypp. 222-226, McGraw Hill Professional, New York, NY, USA, 27 edition, 2016.

[3] G. El Moujaber, M. Osman, R. Rafei, F. Dabboussi, and M. Hamze, "Molecular mechanisms and epidemiology of resistance in Streptococcus pneumoniae in the Middle East region," Journal of Medical Microbiology, vol. 66, no. 7, pp. 847-858, 2017.

[4] World Health Organization, Pneumonia, WHO, Geneva, Switzerland, 2014, http://www.who.int/mediacentre/ factsheets/fs331/en/.

[5] M. S. Morehead and C. Scarbrough, "Emergence of global antibiotic resistance," Primary Care: Clinics in Office Practice, vol. 45, no. 3, pp. 467-484, 2018.

[6] World Health Organization, WHO Publishes List of Bacteria for Which New Antibiotics Are Urgently Needed, WHO, Geneva, Switzerland, 2017.

[7] A. Liberati, D. G. Altman, J. Tetzlaff et al., "The PRISMA statement for reporting systematic reviews and meta-analyses of studies that evaluate health care interventions: explanation and elaboration," PLoS Medicine, vol. 6, no. 7, Article ID e1000100, 2009.

[8] K. M. Gharibani, A. Azami, M. Parvizi, F. Khademi, S. F. Mousavi, and M. Arzanlou, "High frequency of macrolide-resistant Streptococcus pneumoniae colonization in respiratory tract of healthy children in Ardabil, Iran," Tanaffos, vol. 18, no. 2, pp. 118-125, 2019.

[9] A. Khoshdel, R. Imani, A. Saedi et al., "The prevalence of Streptococcus pneumonia and its penicillin resistance pattern in children less than five years old from Shahrekord, Iran, 2007," Journal of Shahrekord University of Medical Sciences, vol. 10, no. 4, pp. 89-95, 2009.

[10] R. Imani, H. Rouhi-Boroujeni, and F. Ganji, "Prevalence of antibiotic resistance among bacteria isolates of lower respiratory tract infection in COPD Shahrekord Iran, 2005," Pakistan Journal of Medical Sciences, vol. 23, no. 3, pp. 438440, 2007.

[11] B. Abdinia, M. A. Rezaee, and S. A. Oskouie, "Etiology and antimicrobial resistance patterns of acute bacterial meningitis in children: a 10-year referral hospital-based study in northwest Iran," Iranian Red Crescent Medical Journal, vol. 16, no. 7, Article ID e17616, 2014. 
[12] N. Hadi and K. Bagheri, "A five-year retrospective multicenter study on etiology and antibiotic resistance pattern of bacterial meningitis among Iranian children," Infection Epidemiology and Microbiology, vol. 5, no. 4, pp. 17-24, 2019.

[13] M. Kargar, F. M. Jahromi, A. Doosti, Z. Mohammadalipour, and S. Lorzadeh, "Resistance to different generations of quinolones in Streptococcus pneumoniae strains isolated from hospitals in Shiraz," Comparative Clinical Pathology, vol. 24, no. 3, pp. 533-536, 2015.

[14] M. M. Kargar, M. Baghernejad, S. Ghorbani-Dalini, and A. Najafi, "Multi-drug resistance and molecular pattern of erythromycin and penicillin resistance genes in Streptococcus pneumoniae," African Journal of Biotechnology, vol. 11, no. 4, pp. 968-973, 2012.

[15] M. Shishegar, A. Faramarzi, T. Kazemi, A. Bayat, and M. Motamedifar, "Polymerase chain reaction, bacteriologic detection and antibiogram of bacteria isolated from otitis media with effusion in children, Shiraz, Iran," Iranian Journal of Medical Sciences, vol. 36, no. 4, pp. 273-280, 2011.

[16] A. Japoni, M. Kalani, S Farshad et al., "Antibiotic-resistant bacteria in hospitalized patients with bloodstream infections: analysis of some associated factors," Iranian Red Crescent Medical Journal, vol. 12, no. 2, pp. 163-171, 2010.

[17] J. Kohanteb and E. Sadeghi, "Penicillin-resistant Streptococcus pneumoniae in Iran," Medical Principles and Practice, vol. 16, no. 1, pp. 29-33, 2007.

[18] E. E. Ghaemi, M. Fazeli, A. Tabaraei, and M. Vakili, "The prevalence of pneumococci throat carrier in healthy school children in Gorgan," Journal of Urmia University of Medical Sciences, vol. 13, no. 1, pp. 16-24, 2002, in Persian.

[19] F. Khademi, A. A. Yousefi, A. Yousefi, P. Karami, K. Ghazvini, and F. Ghanbari, "Prevalence and antimicrobial susceptibility patterns of bacteria isolated from different clinical infections in hamadan, Iran," Infection, Epidemiology and Medicine, vol. 2, no. 3, pp. 8-13, 2016.

[20] R. Yousefi Mashouf, R. Esmaeili, and A. Moshtaghi, "Study of bacterial agents of meningitis in children and detection of their antibiotic resistance patterns in hamadan, Western Iran," International Journal of Medical Investigation, vol. 3, no. 1, pp. 18-24, 2014.

[21] R. Yousefi Mashouf, H. Hashemi, and S. Shams, "Study of bacterial agents of meningitis in children and detection of antibiogram patterns in Hamadan," YAFTEH, vol. 5, no. 17, pp. 31-37, 2004, in Persian.

[22] M. N. Mosleh, M. Gharibi, M. Y. Alikhani, M. Saidijam, and F. Vakhshiteh, "Antimicrobial susceptibility and analysis of macrolide resistance genes in Streptococcus pneumoniae isolated in Hamadan," Iranian Journal of Basic Medical Sciences, vol. 17, pp. 595-599, 2014.

[23] M. N. Mosleh, M. Gharibi, M. Y. Alikhani, M. Saidijam, and G. Kalantarian, "Antimicrobial susceptibilities and distribution of resistance genes for $\beta$-lactams in Streptococcus pneumoniae isolated in Hamadan," Jundishapur Journal of Microbiology, vol. 7, no. 10, Article ID e12714, 2014.

[24] A. Yeganeh-Moghadam, M. Namazi, S. A. Moravveji, A. Khorshidi, and A. Abbasi-Moghadam, "Bacteriological assessment of resistant effusional otitis media discharge among the 2-16 year-old children admitted to Matini hospital in Kashan, 2011-2013," Feyz Journal of Kashan University of Medical Sciences, vol. 18, no. 5, pp. 469-476, 2014, in Persian.

[25] H. M. Ghazikalayeh, R. Moniri, S. G. Moosavi, M. Rezaei, M. Yasini, and M. Valipour, "Serotyping, antibiotic susceptibility and related risk factors aspects of nasopharyngeal carriage of Streptococcus pneumoniae in healthy school students," Iranian Journal of Public Health, vol. 43, no. 9, pp. 1284-1290, 2014.

[26] T. Sabory, K. Ghadiri, R. Abiri, A. Elahi, S. Poormohammadi, and A. R. Gharib, "Incidence of nasopharyngeal carriers of Streptococcus pneumoniae and antibiotic resistance in the children in Kermanshah 2012," Journal of Nursing Education Healio, vol. 4, no. 4, pp. 90-97, 2016, in Persian.

[27] A. D. Khosravi, M. Mehdinejad, and M. Heidari, "Bacteriological findings in patients with ocular infection and antibiotic susceptibility patterns of isolated pathogens," Singapore Medical Journal, vol. 48, no. 8, pp. 741-743, 2007.

[28] N. Moafi and K. Issazadeh, "Frequency of Neonatal and children bacterial meningitis and determining their antibiotic sensitivity patterns in Hospitals of Iran," International Journal of Molecular and Clinical Microbiology, vol. 6, no. 1, pp. 608-612, 2016.

[29] S. Mamishi, M. Mohammadian, B. Pourakbari et al., "Antibiotic resistance and genotyping of gram-positive bacteria causing hospital-acquired infection in patients referring to children's medical center," Infection and Drug Resistance, vol. 12, pp. 3719-3726, 2019.

[30] S. H. Ghahfarokhi, M. Mosadegh, A Ahmadi et al., "Serotype distribution and antibiotic susceptibility of Streptococcus pneumoniae isolates in Tehran, Iran: a surveillance study," Infection and Drug Resistance, vol. 13, pp. 333-340, 2020.

[31] M. Azarsa, S. Ohadian Moghadam, M. Rahbar, Z. Baseri, and M. R. Pourmand, "Molecular serotyping and genotyping of penicillin non-susceptible pneumococci: the introduction of new sequence types, Tehran, Iran," New Microbes and New Infections, vol. 32, Article ID 100597, 2019.

[32] S. F. Mousavi, B. Mirzaei, B. Shaghaghi, P. Jalali, T. Setayesh, and S. H. Moosavi, "Phenotypic and genotypic features of first biofilm forming nasopharyngeal colonized Streptococcus pneumoniae isolates," Iranian Journal of Microbiology, vol. 9, no. 4, pp. 200-207, 2017.

[33] A. Ahmadi, S. Yaghoubi, and G. Irajian, "Molecular analysis of PBP1A inStreptococcus pneumoniaeIsolated from clinical and normal flora samples in Tehran, Iran: a multicenter study," Microbial Drug Resistance, vol. 25, no. 1, pp. 39-46, 2019.

[34] H. Houri, S. R. Tabatabaei, Y. Saee, F. Fallah, M. Rahbar, and A. Karimi, "Distribution of capsular types and drug resistance patterns of invasive pediatric Streptococcus pneumoniae isolates in Teheran, Iran," International Journal of Infectious Diseases, vol. 57, pp. 21-26, 2017.

[35] M. Talebi, J. Sadeghi, A. Ahmadi, V. Lohrasbi, P. Owlia, and M. R. Pourshafie, "High rate of serotype switching and genetic variations indicates Widespread recombination between clinical and commensal penicillin-nonsusceptible Streptococcus pneumoniae in Tehran," Microbial Drug Resistance, vol. 25, no. 6, pp. 865-873, 2019.

[36] M. S. Moghadam, M. Talebi, F. Masjedian, G. Irajian, and M. R. Pourshafie, "Streptococcus pneumoniae serotyping by a single polymerase chain reaction-based multiplex assay," Infectious Diseases in Clinical Practice, vol. 26, no. 2, pp. 75-79, 2018.

[37] A. A. Farshad, M. Enferadi, S. Bakand, R. Jamshidi Orak, and R. Mirkazemi, "Penicillin dust exposure and penicillin resistance among pharmaceutical workers in Tehran, Iran," International Journal of Occupational and Environmental Health, vol. 22, no. 3, pp. 218-223, 2016.

[38] M. Rahbar, A. Dolatyar Dehkharghani, S. M. Zahraei, M. Mardani, and M. Mohammadzadeh, "Antimicrobial resistance in Streptococcus pneumoniae isolates from invasive 
pneumococcal infections in Iran," Journal of Global Antimicrobial Resistance, vol. 16, pp. 260-261, 2019.

[39] S. R. Tabatabaei, M. Rahbar, A. N Alam et al., "Detection of $p b p 2 b$ gene and antimicrobial susceptibility pattern of Streptococcus pneumoniae isolates in Tehran hospitals, Iran," Archives of Pediatric Infectious Diseases, vol. 5, no. 1, Article ID e38891, 2017.

[40] M. Talebi, A. Azadegan, J Sadeghi et al., "Determination of characteristics of erythromycin resistant Streptococcus pneumoniae with preferred PCV usage in Iran," PLoS One, vol. 11, no. 12, Article ID e0167803, 2016.

[41] A. Azadegan, A. Ahmadi, A. R. Lari, and M. Talebi, "Detection of the efflux-mediated erythromycin resistance transposon in Streptococcus pneumoniae," Annals of Laboratory Medicine, vol. 35, no. 1, pp. 57-61, 2015.

[42] S. Abdollahi, S. D. Siadat, R Shapouri et al., "Antibiotic susceptibility and prevalence of adhesion genes in Streptococcus pneumoniae isolates detected in carrier children in Tehran," Jundishapur Journal of Microbiology, vol. 11, no. 6, Article ID e13256, 2018.

[43] A. Ahmadi, M. Talebi, and G. Irajian, "High prevalence of erythromycin- and tetracycline-resistant clinical isolates of Streptococcus pneumoniae in Iran," Infectious Diseases in Clinical Practice, vol. 21, no. 5, pp. 299-301, 2013.

[44] M. M. Soltan Dallal, H. Jabbari, A. Rahimi Forushani, S. Heidarzadeh, P. Afrogh, and M. K. Sharifi Yazdi, "Frequency and resistance patterns of Streptococcus pneumoniae in acute otitis media," Journal of Mazandaran University of Medical Sciences, vol. 23, no. 98, pp. 28-35, 2013, in Persian.

[45] J. Sadeghi, A. Ahamadi, M. Douraghi, M. R. Pourshafie, and M. Talebi, "Molecular analysis of pbp2b in Streptococcus pneumonia isolated from clinical and normal flora samples," Current Microbiology, vol. 70, no. 2, pp. 206-211, 2015.

[46] A. Ahmadi, M. Esghaei, G. Irajian, and M. Talebi, "Differentiation of penicillin susceptible and nonsusceptible Streptococcus pneumoniae," Journal of Medical Bacteriology, vol. 4, no. 1-2, pp. 15-20, 2015.

[47] S. Mahmoudi, H. Zandi, B. Pourakbari, M. T. H. Ashtiani, and S. Mamishi, "Acute bacterial meningitis among children admitted into an Iranian referral children's hospital," Japanese Journal of Infectious Diseases, vol. 66, no. 6, pp. 503-506, 2013.

[48] S. S. Khoramrooz, A. Mirsalehian, M. Emaneini et al., "Frequency of Alloicoccus otitidis, Streptococcus pneumoniae, Moraxella catarrhalis and Haemophilus influenzae in children with otitis media with effusion (OME) in Iranian patients," Auris Nasus Larynx, vol. 39, no. 4, pp. 369-373, 2012.

[49] F. Rahimi, M. N. Hashemian, A. Khosravi, G. Moradi, and S. Bamdad, "Bacterial keratitis in a tertiary eye centre in Iran: a retrospective study," Middle East African Journal of Ophthalmology, vol. 22, no. 2, pp. 238-244, 2015.

[50] S. Habibian, A. Mehrabi-Tavana, Z Ahmadi et al., "Serotype distribution and antibiotics susceptibility pattern of Streptococcus pneumonia in Iran," Iranian Red Crescent Medical Journal, vol. 15, no. 10, Article ID e8053, 2013.

[51] A. Sanaei Dashti, B. Abdinia, and A. Karimi, "Nasopharyngeal carrier rate of Streptococcus pneumoniae in children: serotype distribution and antimicrobial resistance," Archives of Iranian Medicine, vol. 15, no. 8, pp. 500-503, 2012.

[52] M. T. Ashtiani, M. Sadeghian, B. Nikmanesh, B. Pourakbari, S. Mahmoudi, and S. Mamishi, "Antimicrobial susceptibility trends among Streptococcus pneumoniae over an 11-year period in an Iranian referral children hospital," Iran Journal of Microbiology, vol. 6, no. 6, pp. 382-386, 2014.
[53] B. Pourakbari, A. Sadr, M. T Ashtiani et al., "Five-year evaluation of the antimicrobial susceptibility patterns of bacteria causing bloodstream infections in Iran," Journal of Infection in Developing Countries, vol. 6, no. 02, pp. 120-125, 2012.

[54] M. Aligholi, M. Emaneini, F Jabalameli et al., "Antibiotic susceptibility pattern of gram-positive cocci cultured from patients in three university hospitals in Tehran, Iran during 2001-2005," Acta Medica Iranica, vol. 47, no. 4, pp. 329-334, 2009.

[55] M. Oskoui, S. Nobari, F. Rahmati Ghezelgeh, B. Shaghaghi, and N. Amirmozafari, "Molecular characterization of PBP2b in clinical isolates of Streptococcus pneumoniae," Iranian Journal of Medical Microbiology, vol. 4, no. 1 and 2, pp. 9-16, 2010, in Persian.

[56] S. A. H. Jahanmehr, A. Rajabi, M. Soltani Radd, and G. H. Behzadian Nejad, "The resistance of Streptococcus pneumoniae against penicillin and other antibiotics," Acta Medica Iranica, vol. 42, no. 3, pp. 223-227, 2004.

[57] M. Oskoui, M. Feyzabadi, and A. Amirkhani, "Drug susceptibility of Streptococcus pneumoniae strains isolated in Tehran, Iran," Archives of Iranian Medicine, vol. 6, no. 3, pp. 192-195, 2003.

[58] G. Rezaeizadeh, B. Pourakbari, M. H. Ashtiani, F. Asgari, S. Mahmoudi, and S. Mamishi, "Antimicrobial susceptibility of bacteria isolated from cerebrospinal fluids in an Iranian referral pediatric center, 1998-2008," Maedica, vol. 7, no. 2, pp. 131-137, 2012.

[59] S. H. Modarres, A. Lasheii, and N. N. Oskoii, "Bacterial etiologic agents of ocular infection in children in the Islmic Republic of Iran," East Mediterr Health Journal, vol. 4, no. 1, pp. 44-49, 1998.

[60] Z. Gharailoo, S. F. Mousavi, N. Halvani, and M. M. Feizabadi, "Antimicrobial resistant pattern and capsular typing of Streptococcus pneumoniae isolated from children in Sistan-Baluchestan,” Moedica.vol. 11, no. 3, pp. 203-207, 2016.

[61] M. Bokaeian, H. A. Khazaei, and M. Javadimehr, "Serotype distribution and antimicrobial resistance of invasive Streptococcus pneumoniae isolates from children in Zahedan, Iran," African Journal of Microbiology Research, vol. 6, no. 1, pp. 28-33, 2012.

[62] M. Bokaeian, H. A. Khazaei, and M. Javadimehr, "Nasopharyngeal carriage, antibiotic resistance and serotype distribution of Streptococcus pneumoniae among healthy adolescents in Zahedan," Iranian Red Crescent Medical Journal, vol. 13, no. 5, pp. 328-333, 2011.

[63] M. Rahbar, R. Gra-Agaji, and S. Hashemi, "Nosocomial blood stream infections in Imam Khomeini hospital, Urmia, Islamic Republic of Iran, 1999-2001," Eastern Mediterranean health journal $=$ La revue de sante de la Mediterranee orientale $=$ alMajallah al-sihhiyah li-sharq al-mutawassit, vol. 11, no. 3, pp. 478-484, 2005.

[64] F. Behnaz, L. Firousabadi, A. Babaei-Zadeh, and M. Mohammad - Zadeh, "Prevalence of pharyngeal pneumococcal carriers and succeptibility patterns among children of day care centers in Yazd district, Iran," JSSU, vol. 12, no. 1, pp. 65-69, 2004, in Persian.

[65] A. Karami, M. Panahi, and A. Karami, "Determination of pneumococcal MIC to antibiotics in pneumococcus strains isolated from Zanjan hospitals," JQUMS, vol. 13, no. 2, pp. 17-22, 2009, in Persian.

[66] Z. Munn, S. Moola, K. Lisy, D. Riitano, and C. Tufanaru, "Methodological guidance for systematic reviews of observational epidemiological studies reporting prevalence and 
cumulative incidence data," International Journal of EvidenceBased Healthcare, vol. 13, no. 3, pp. 147-153, 2015.

[67] S. J. Hoffman, K. Outterson, J.-A. Røttingen et al., “An international legal framework to address antimicrobial resistance," Bull World Health Organ, vol. 93, p. 66, 2016.

[68] R. R. Reinert, "The antimicrobial resistance profile of Streptococcus pneumoniae," Clinical Microbiology and Infection, vol. 15, no. Suppl. 3, pp. 7-11, 2009.

[69] T. C. Pinto, F. P. Neves, A. R Souza et al., "Evolution of penicillin non-susceptibility among Streptococcus pneumoniae isolates recovered from asymptomatic carriage and invasive disease over 25 years in Brazil, 1990-2014," Frontiers in Microbiology, vol. 10, p. 486, 2019.

[70] C. Zhao, Z. Li, F Zhang et al., "Serotype distribution and antibiotic resistance of Streptococcus pneumoniae isolates from 17 Chinese cities from 2011 to 2016," BMC Infect Dis, vol. 17, no. 1, p. 804, 2017.

[71] R. Cherazard, M. Epstein, T.-L. Doan, T. Salim, S. Bharti, and M. A. Smith, "Antimicrobial resistant Streptococcus pneumoniae: prevalence, mechanisms, and clinical implications," American Journal of Therapeutics, vol. 24, no. 3, pp. e361e369, 2017.

[72] P. J. Ceyssens, F. Van Bambeke, W Mattheus et al., "Belgian Streptococcus pneumoniae Study Group. Molecular analysis of rising fluoroquinolone resistance in Belgian non-invasive Streptococcus pneumoniae isolates (1995-2014)," PLoS One, vol. 11, no. 5, Article ID e0154816, 2016.

[73] Centers for Disease Control and Prevention, Antibiotic Resistance Threats in the United States, Centers for Disease Control and Prevention, Atlanta, GA, USA, 2019.

[74] S. B. Levy and B. Marshall, "Antibacterial resistance worldwide: causes, challenges and responses," Nature Medicine, vol. 10, no. 12, pp. S122-S129, 2004. 